\title{
Potential Biomarkers for NSAID-Exacerbated Respiratory Disease
}

\author{
Hanki Park, ${ }^{1}$ Youngwoo Choi, ${ }^{2}$ Chang-Gyu Jung, ${ }^{2}$ and Hae-Sim Park ${ }^{2}$ \\ ${ }^{1}$ Department of Allergy and Clinical Immunology, Kyungpook National University School of Medicine, Daegu, Republic of Korea \\ ${ }^{2}$ Department of Allergy and Clinical Immunology, Ajou University Medical Center, Suwon, Republic of Korea
}

Correspondence should be addressed to Hae-Sim Park; hspark@ajou.ac.kr

Received 16 May 2017; Accepted 26 July 2017; Published 9 August 2017

Academic Editor: Younghyo Kim

Copyright (c) 2017 Hanki Park et al. This is an open access article distributed under the Creative Commons Attribution License, which permits unrestricted use, distribution, and reproduction in any medium, provided the original work is properly cited.

Asthma is a common chronic disease with several variant phenotypes and endotypes. NSAID-exacerbated respiratory disease (NERD) is one such endotype characterized by asthma, chronic rhinosinusitis (CRS) with nasal polyps, and hypersensitivity to aspirin/cyclooxygenase-1 inhibitors. NERD is more associated with severe asthma than other asthma phenotypes. Regarding diagnosis, aspirin challenge tests via the oral or bronchial route are a standard diagnostic method; reliable in vitro diagnostic tests are not available. Recent studies have reported various biomarkers of phenotype, diagnosis, and prognosis. In this review, we summarized the known potential biomarkers of NERD that are distinct from those of aspirin-tolerant asthma. We also provided an overview of the different NERD subgroups.

\section{Introduction}

NSAID-exacerbated respiratory disease (NERD) is characterized by adult-onset chronic rhinosinusitis (CRS) with nasal polyps, intense eosinophilic infiltration in the upper and lower airway mucosa, and severe symptoms of exacerbation in response to aspirin/cyclooxygenase- (COX-) 1 inhibitors [1]. A previous systematic review had reported a NERD prevalence of $7 \%$ among typical adult asthmatic patients and twice among patients with severe asthma [2]. NERD is therefore considered a risk factor for severe asthma [3, 4]. Among patients with CRS and nasal polyps, the prevalence of NERD was $8.7 \%$ and $9.7 \%$, respectively [2]. NERD is associated with severe CRS with nasal polyps, recurrence after sinus surgery, and airway remodeling [5-7], suggesting that NERD causes severe asthma with CRS/nasal polyps.

NERD has a unique pathophysiology, with increased levels of lipid mediators, activated eosinophils, and mast cells, even without COX-1 inhibitor treatment. Thus, in most studies defining asthma endotypes, NERD has been identified as an independent endotype [8, 9]. However, all patients with NERD are not accompanied by severe asthma, and their clinical course is also known to be variable [10]. Confirmative diagnosis of NERD is based on provocation tests with aspirin. Oral aspirin challenge is considered the gold standard diagnostic method; however, its use is often limited by the risk of severe reactions during the test. The bronchial aspirin challenge is safer and consumes less time; however, it is limited by its low sensitivity [11]. In addition, oral or bronchial aspirin challenge test has limitations that cannot be used to predict the treatment or prognosis of NERD. Therefore, in vitro tests should be developed for diagnosing and monitoring NERD.

In this review, we summarized three groups of known noninvasive biomarkers that can distinguish NERD from aspirin-tolerant asthma (ATA): lipid mediators, inflammatory cells and cytokines, and genetic markers. In addition, we reviewed the subtypes of NERD and the related biomarkers for developing precision medicine in the future.

\section{NERD as an Endotype of Asthma}

Recently, many studies were conducted to distinguish asthma phenotypes and endotypes that affect diagnosis, treatment choice, and prognosis. A phenotype refers to "clinically observable characteristics," and it is distinguished by clinical features, pathophysiological factors, response to treatment, prognosis, and so on [12]. An endotype is a subtype of a disease that is functionally and pathologically defined by a molecular mechanism or a treatment response [13]. 
TABLE 1: Lipid mediators.

\begin{tabular}{|c|c|c|c|c|c|c|c|}
\hline & \multirow[b]{2}{*}{$\begin{array}{l}\text { Mediators and } \\
\text { parameters }\end{array}$} & \multirow[b]{2}{*}{$\begin{array}{l}\text { Biologic } \\
\text { sample }\end{array}$} & \multirow[b]{2}{*}{ Detection method } & \multicolumn{2}{|c|}{ Baseline } & \multicolumn{2}{|c|}{ Response after ASA provocation } \\
\hline & & & & $\begin{array}{c}\text { Compared } \\
\text { to ATA }\end{array}$ & Reference & $\begin{array}{c}\text { Compared to } \\
\text { ATA }\end{array}$ & Reference \\
\hline & \multirow{6}{*}{ LTE4 } & \multirow{2}{*}{ Urine } & Immunoassay & $\uparrow$ & {$[25,28-34]$} & $\uparrow$ & {$[25,28,30,31,34]$} \\
\hline & & & Mass spectrometry & $\uparrow$ & {$[35,36]$} & $\uparrow$ & {$[36]$} \\
\hline & & Saliva & Immunoassay & $\uparrow$ & {$[25]$} & $\uparrow$ & [27] \\
\hline & & \multirow{2}{*}{$\begin{array}{l}\text { Induced } \\
\text { sputum }\end{array}$} & Immunoassay & $\uparrow$ & {$[25]$} & & \\
\hline & & & Mass spectrometry & $\uparrow$ & {$[26]$} & $\uparrow$ & {$[26]$} \\
\hline & & $\begin{array}{l}\text { Blood and } \\
\text { urine }\end{array}$ & $\begin{array}{l}\text { Untargeted metabolomic } \\
\text { analysis }\end{array}$ & $\uparrow$ & {$[37]$} & & \\
\hline \multirow{6}{*}{$\begin{array}{l}\text { COX } \\
\text { pathway }\end{array}$} & \multirow{2}{*}{ PGD2 } & \multirow{2}{*}{$\begin{array}{l}\text { Induced } \\
\text { sputum }\end{array}$} & Immunoassay & $\uparrow$ & {$[32]$} & & \\
\hline & & & Mass spectrometry & $\uparrow$ & {$[26]$} & & \\
\hline & \multirow{3}{*}{ PGD2 metabolite } & \multirow{2}{*}{ Spot urine } & Immunoassay & & & $\uparrow$ & {$[31,33]$} \\
\hline & & & Mass spectrometry & $\uparrow$ & {$[41]$} & $\uparrow$ & {$[41]$} \\
\hline & & Blood & Mass spectrometry & $\uparrow$ & {$[40]$} & $\uparrow$ & {$[40,42]$} \\
\hline & PGE2 & Spot urine & Immunoassay & $\downarrow$ & [33] & & \\
\hline \multirow{2}{*}{ Others } & \multirow{2}{*}{$\begin{array}{l}\text { Sphingolipid } \\
\text { metabolite }\end{array}$} & Blood & Mass spectrometry & $\uparrow$ & [48] & $\downarrow$ & [48] \\
\hline & & Spot urine & Mass spectrometry & $\uparrow$ & {$[48]$} & & \\
\hline
\end{tabular}

ATA: aspirin-tolerant asthma; LO: lipoxygenase; LT: leukotriene; COX: cyclooxygenase; PG: prostaglandin.

Although there is no widely accepted method for endotyping, most studies have classified NERD as an endotype of asthma $[9,12]$. NERD is known to be a late-onset asthma, as the first symptoms usually start at the age of $20 \sim 40$ years; females are more affected, and it is not influenced by family history or geographic region [14]. Rhinitis is usually the first observed symptom followed by asthma, sensitivity to aspirin, and nasal polyps [15]. Patients with NERD presented with moderate to severe asthma (with frequent exacerbation) have poor lung function and require more frequent intubation and systemic steroid bursts [6].

The pathophysiological features of NERD include lipid mediator imbalance and intense eosinophilic inflammation. Proinflammatory cysteinyl leukotrienes (cysLTs) and prostaglandin (PG) D2 (PGD2) are known to be markedly upregulated in NERD, whereas PGE2 has been found to be constitutively decreased [16-18]. Patients with NERD have a higher number of mast cells and eosinophils infiltrating the upper and lower respiratory mucosa, even without exposure to COX-1 inhibitors and changes in tissue eicosanoid metabolism [19-21]. In NERD, cytokines and chemokines show a trend of Th2 immune response [22, 23].

\section{Biomarkers of NERD}

3.1. Lipid Mediators. The most reproducible and informative biomarker to distinguish NERD from ATA is a high-level urinary LTE4 (Table 1). LTE4 is the substance last metabolized in cysLTs. LTC4 and LTD4 are easily metabolized in the following stages, while LTE4 is released into the urine in a stable manner; it is therefore suitable for use as a biomarker [24]. The LTE4 levels in induced sputum and saliva are higher in NERD than in ATA [25-27]. However, urinary LTE4, which indirectly reflects the activity of cysLTs in the lungs, has been used to distinguish NERD from ATA in many studies [25, 28-36]. In addition, the nature of the urine specimen makes it easier to standardize the level of LTE4, and it has the advantage of noninvasiveness. The value of urinary LTE4 is increased, in the baseline as well as under aspirin or COX-1 inhibitor provocation, in NERD compared to ATA. Thus, baseline urinary LTE4 can be used as a biomarker to distinguish NERD from ATA. This phenomenon is present in both random urine and $24 \mathrm{~h}$ urine; recent studies on $24 \mathrm{~h}$ urine have reported an area under the curve (AUC) of 0.87 [35]. In addition, it was confirmed that the metabolites of urinary LTE4 were significantly different in NERD and ATA, even in studies that used metabolomics [37]. Urinary LTE4 can be used not only to distinguish between NERD and ATA but also to indicate the prognosis and treatment response. Urinary LTE4 is associated with a decrease in FEV1 during aspirin challenge in patients with NERD [38]. It has been reported that urinary LTE4 is significantly higher in patients with NERD who failed in aspirin desensitization than in patients who achieved aspirin desensitization successfully [36]. Although urinary LTE4 is also increased in allergic asthma, eosinophilic asthma, and severe asthma without NERD, it can be used as a biomarker in patients with NERD, as it shows a remarkable increase in NERD, compared to ATA; it can therefore be used for predicting treatment response and prognosis.

PGD2 and PGE2, which are counteracted by the products of cyclooxygenase, are known to be closely related to the pathogenesis of NERD, but their use as biomarkers is still limited. PGD2 is mainly secreted from mast cells and eosinophils and is known to act as a proinflammatory and bronchoconstrictive mediator through CRTH2 [39]. Baseline PGD2 has been observed to be significantly increased in induced sputum [26]. PGD2 metabolites in urine and blood are also 
TABLE 2: Cellular and cytokine markers.

\begin{tabular}{|c|c|c|c|c|c|c|c|}
\hline & \multirow{2}{*}{$\begin{array}{l}\text { Mediators and } \\
\text { parameters }\end{array}$} & \multirow{2}{*}{$\begin{array}{l}\text { Biologic } \\
\text { sample }\end{array}$} & \multirow{2}{*}{ Detection method } & \multicolumn{2}{|c|}{ Baseline } & \multicolumn{2}{|c|}{$\begin{array}{l}\text { Response after aspirin } \\
\text { provocation }\end{array}$} \\
\hline & & & & $\begin{array}{c}\text { Compared } \\
\text { to ATA }\end{array}$ & Reference & $\begin{array}{c}\text { Compared } \\
\text { to ATA }\end{array}$ & Reference \\
\hline \multirow{3}{*}{ Cell } & Eosinophil & NALF & $\begin{array}{l}\text { Morphological count } \\
\text { of stained slide }\end{array}$ & & & $\uparrow$ & {$[52]$} \\
\hline & Platelet-adherent leukocyte & blood & Flow cytometry & $\uparrow$ & [65] & & \\
\hline & Soluble platelet surface marker & blood & Immunoassay & $\uparrow$ & [64] & & \\
\hline \multirow{2}{*}{ Others } & ECP & NALF & Immunoassay & & & $\uparrow$ & [27] \\
\hline & Periostin & Blood & Immunoassay & $\uparrow$ & [57] & & \\
\hline
\end{tabular}

ATA: aspirin-tolerant asthma; NALF: nasal lavage fluid; ECP: eosinophil cationic protein.

increased after aspirin provocation [40-42]. However, these results differ among studies, and the range of overlap is wide; therefore, the use of PGD2 as a biomarker of NERD to distinguish it from ATA is limited. A previous study had reported that urinary PGD2 metabolites reflect the difference between tolerant and intolerant groups during aspirin desensitization in patients with NERD [36]. Further studies are required to validate the use of PGD2 as a biomarker for predicting the treatment response and prognosis of NERD. PGE2 is considered a key mediator in the pathogenesis of NERD. Unlike cysLTs or PGD2, it is known to have anti-inflammatory and bronchoprotective effects in airway inflammation. Inhaled PGE2 prevents bronchoconstriction and cysLT production in NERD [43]. Most urinary PGE2 metabolites are derived from COX-2, and several studies have demonstrated that airway tissues in patients with NERD showed impaired expression of COX-2 [44, 45]. Apart from one study that suggested decreased baseline PGE2 levels in NERD [33], most studies showed no significant differences in the levels of PGE2 or its metabolites between NERD and ATA groups, indicating that further investigations are needed to evaluate its use as a potential therapeutic target.

The lipid mediators, not the arachidonic acid metabolites, have also been studied as biomarkers of NERD, especially sphingolipid metabolites. Sphingolipid metabolites mediate cell growth, cell differentiation, cell death, and autophagy, and the dysregulation of sphingolipid metabolism could induce airway inflammation and bronchial hyperreactivity $[46,47]$. Baseline levels of serum sphingosine-1-phosphate (S1P) and urine sphingosine were significantly increased in patients with NERD, and a significant correlation with a decrease in FEV1 has been observed after aspirin challenge [48]. Sphingolipid metabolites may be possible biomarkers for NERD, although further studies are needed to validate their use.

3.2. Inflammatory Cells and Cytokines. The cellular pathogenic mechanism in NERD involves an intense eosinophilic inflammation, in which Th2 immunity orchestrates the phenotype of eosinophilic asthma (Table 2). Based on these findings, various studies have reported the eosinophil count, eosinophil-related mediators, and Th2 cytokines as biomarkers of NERD. Sputum and blood eosinophil counts are biomarkers for asthma phenotype of airway eosinophilic inflammation [49]. NERD is characterized by phenotypes represented by adult-onset eosinophilic asthma. Furthermore, local eosinophilia has been observed in the nasal polyp tissues or the bronchial lavage fluid of patients with NERD as well as blood eosinophilia [21, 50-52]. Therefore, sputum and blood eosinophil counts are difficult to use as direct diagnostic biomarkers of NERD, but they are important as biomarkers in distinguishing eosinophilic inflammation, one of the pathogenesis of NERD. Sputum and blood eosinophil counts are biomarkers that are also useful in predicting asthma severity and response to therapy [53, 54]. Therefore, sputum and blood eosinophil counts are biomarkers that can be used to evaluate the severity of NERD and the response to therapy. Among all the mediators of Th2 immunity, the biomarker most associated with NERD is periostin. Periostin is an extracellular matrix protein that is known to regulate inflammation/remodeling of the asthmatic airway [55]. Periostin is known to be a surrogate marker of Th2 immunity [56]. In a study on 277 adult asthmatic patients, we showed that serum periostin was a useful biomarker of NERD and that it could be used as an index of blood/sputum eosinophilia and asthma severity [57]. This study showed that it is useful as a biomarker to predict NERD $(p=0.006)$ even after multivariate regression analysis, which is more efficient than predictions of severe asthma phenotype $(p=0.04)$. This suggests that periostin is a potential independent biomarker of NERD diagnosis. Various other Th2 cytokines and chemokines, including IL-4, IL-5, IL-13, IL-33, TSLP, GM-CSF, and eotaxin have been studied, and some studies have shown statistically significant differences in their levels [58, 59]. In addition, cytokines such as IL-6, IL-8, and IFN-r have also been associated with AERD $[60,61]$, although further studies will be needed to validate their clinical significances.

Platelet activation is associated with leukocytes, which promote the secretion of proinflammatory lipid mediators such as cysLTs in NERD. Platelet activation induces the expression of cell adhesion molecules on the extracellular surface, which bind to the leukocytes through P-selectin (CD62P)-P-selectin glycoprotein ligand 1, GPIIb/IIIa-Mac1 , and CD40 ligand (CD40L)-CD40 [62, 63]. Recent studies have reported an increased percentage of platelet-adherent leukocytes and platelet activation markers such as sPselectin and SCD40L in the blood of patients with NERD. These phenomena contribute to the overproduction of 
TABLE 3: Potential genetic markers.

\begin{tabular}{|c|c|c|c|c|c|c|}
\hline & Gene & Polymorphisms & Patients & $\begin{array}{l}\text { Ethnic } \\
\text { group }\end{array}$ & Mechanism & Reference \\
\hline \multirow{6}{*}{$\begin{array}{l}\text { Arachidonic } \\
\text { acid } \\
\text { metabolism }\end{array}$} & CYSLTR1 & $\begin{array}{c}\quad 634 \mathrm{C}>\mathrm{T}, \quad 475 \mathrm{~A}>\mathrm{C} \\
\_336 \mathrm{~A}>\mathrm{G}\end{array}$ & $\begin{array}{c}\text { NERD: } 105 \text {, ATA: } 110 \text {, } \\
\text { NC: } 125\end{array}$ & Korean & CysLTR1 expression & {$[74]$} \\
\hline & CYSLTR2 & $\begin{array}{c}819 \mathrm{~T}>\mathrm{G}, 2078 \mathrm{C}>\mathrm{T} \\
2534 \mathrm{~A}>\mathrm{G}\end{array}$ & $\begin{array}{l}\text { NERD: } 134, \text { ATA: } 66 \\
\text { NC: } 152\end{array}$ & Korean & $\begin{array}{l}\text { CysLTR2 expression, } \\
\text { LTC4S gene interaction }\end{array}$ & {$[75]$} \\
\hline & EP2 & uS5, uS5b, uS7 & $\begin{array}{l}\text { NERD: } 198, \text { ATA: } 282 \text {, } \\
\text { NC: } 274\end{array}$ & Japanese & $\begin{array}{c}\text { Decrease transcription } \\
\text { level of EP2, PGE2 } \\
\text { braking }\end{array}$ & {$[76]$} \\
\hline & PTGER & $\begin{array}{c}\text { PTGER2:_616 C>G, } \\
\text { 166 G>A } \\
\text { PTGER3:_1709 T>A, } \\
\text { PTGER4:_1254 A>G }\end{array}$ & $\begin{array}{c}\text { NERD: } 108, \\
\text { ATA: } 93, \text { NC: } 140\end{array}$ & Korean & $\begin{array}{l}\text { PGE2, TXA2 receptor } \\
\text { polymorphism }\end{array}$ & {$[77]$} \\
\hline & TBXA2R & $-4684 \mathrm{C}>, 795 \mathrm{~T}>\mathrm{C}$ & & & & \\
\hline & PTGER & $\begin{array}{c}\text { PTGER3: rs7543182, } \\
\text { rs959 }\end{array}$ & $\begin{array}{l}\text { NERD: } 243 \text {, } \\
\text { ATA: } 918\end{array}$ & Korean & $\begin{array}{l}\text { PGE2 receptor } \\
\text { polymorphism }\end{array}$ & {$[78]$} \\
\hline \multirow{2}{*}{$\begin{array}{l}\text { Eosinophil- } \\
\text { associated } \\
\text { gene }\end{array}$} & CRTH2 & $-446 \mathrm{~T}>\mathrm{C}$ & $\begin{array}{c}\text { NERD: } 107, \text { ATA: } 115 \text {, } \\
\text { NC: } 133\end{array}$ & Korean & $\begin{array}{c}\text { Decrease CRTH2 } \\
\text { expression and increase } \\
\text { eotaxin-2 production }\end{array}$ & {$[79]$} \\
\hline & CCR3 & $-520 \mathrm{~T}>\mathrm{C}$ & NERD: 94, ATA: 152 & Korean & $\begin{array}{c}\text { Higher mRNA } \\
\text { expression of CCR3 }\end{array}$ & {$[80]$} \\
\hline \multirow{4}{*}{ HLA } & HLA-DPB1 & $\mathrm{DPB} 1^{*} 0301$ & $\begin{array}{l}59 \text { NERD, } 57 \text { ATA, } \\
48 \text { NC }\end{array}$ & Polish & & {$[66]$} \\
\hline & HLA-DPB1 & $\mathrm{DPB} 1^{*} 0301$ & $\begin{array}{c}76 \text { NERD, } 73 \text { ATA, } \\
91 \text { NC }\end{array}$ & Korean & & {$[68]$} \\
\hline & HLA-DPB1 & rs3128965 & $\begin{array}{c}264 \text { NERD, } 387 \text { ATA, } \\
238 \text { NC }\end{array}$ & Korean & & {$[70]$} \\
\hline & HLA-DPB1 & rs1042151 & 117 NERD, 685 ATA & Korean & & {$[69]$} \\
\hline
\end{tabular}

NERD: NSAID-exacerbated respiratory disease; ATA: aspirin-tolerant asthma; CysLTR: cysteinyl leukotriene receptor, LT: leukotriene; PG: prostaglandin; TX: thromboxane; CRTH: chemoattractant receptor homologue expressed by type 2 helper T cells; CCR: chemokine receptor; HLA: human leukocyte antigen; DPP: dipeptidyl peptidase.

cysLTs $[64,65]$. Thus, activated platelet surface markers are possible biomarkers for NERD, although further studies are needed to validate their use.

3.3. Genetic Markers. Various genetic polymorphisms have been reported through genetic association studies of targeted genes (lipid mediators and inflammatory responses) associated with the pathogenesis of NERD. In addition, a number of genome-wide association studies (GWAS) and epigenetic studies have reported potential genetic markers that distinguish NERD from ATA (Table 3).

First, the prevalence of HLA-DPB $1^{*} 0301$ was significantly higher in patients with NERD in a Polish population; the same results were obtained in a study on a Korean population as well [66-68]. The patients carrying this marker had higher prevalence of CRS/nasal polyps than those who had no marker. Furthermore, GWASs demonstrated significant association of two SNPs of HLA-DPB1 (rs1042151 and rs3128965) and susceptibility to NERD $[69,70]$, suggesting HLA-DPB1 may be a strong genetic marker for predicting the NERD phenotype.

Genetic polymorphisms related to arachidonic acid metabolism and their receptor have been reported in candidate gene association studies. Leukotriene C4 synthase (LTC4S) is an important enzyme involved in the production of cysLTs. The gene that encodes LTC4S has been extensively studied for variations; however, it has been found to vary widely, depending on ethnic groups. In the study in the Polish population, which was the first study, it was possible to distinguish between NERD and ATA [71]. However, a recent meta-analysis did not show any significant results in NERD; the only significant results were obtained in the ATA and Caucasian subgroups [72]. In a Korean study, ALOX5 (5-LO enzyme gene) ht1 [G-C-G-A] was found to be significantly higher in NERD than in ATA in the 4SNP $(-1708 \mathrm{G}>\mathrm{A}, 21 \mathrm{C}>\mathrm{T}, 270 \mathrm{G}>\mathrm{A}$, and 1728G $>\mathrm{A})$ [73]. Two groups of receptors, cysLT receptors (CysLTR1, CysLTR2) and PGE2 (EP1, EP2, EP3, and EP4) receptor polymorphisms, have been demonstrated differences in polymorphism between NERD and ATA [74-78].

Several genetic markers associated with eosinophil activation have been reported. CRTH2 in response to PGD2, and CCR3 in response to eotaxin and RANTES, could induce eosinophil activation and recruitment. Polymorphisms in CRTH2 $(-466 \mathrm{~T}>\mathrm{C})$ and CCR3 $(-520 \mathrm{~T}>\mathrm{C})$ were associated with NERD $[79,80]$ and higher levels of eotaxin 2, indicating that the two SNPs of CRTH2 and CCR may be potential genetic markers that represent eosinophil activation in the upper and lower airway inflammation in NERD. Mast cells were also found with genetic polymorphisms that distinguish 
between NERD and ATA. The genotype frequency of FCER1G-237A $>$ G was significantly different in patients with NERD, and patients with ATA and FCERIA-344C $>\mathrm{T}$ and FceR1 $\beta-109 \mathrm{~T}>\mathrm{C}$ polymorphisms were associated with staphylococcal enterotoxin-specific IgE antibodies [81, 82].

So far, most genetic markers have been reported based on pathogenesis only. No genetic markers have been identified repeatedly in different patient groups, except HLA-DPB1. Further studies on diverse populations are required.

\section{NERD Subtypes and Their Biomarkers}

Although NERD is an endotype of asthma, it has been found in diverse phenotypes. Not all patients with NERD exhibit CRS and nasal polyps. The severity and response to treatment varies among patients. Recently, two studies of clustering in NERD cohorts were reported. The first study clustered 201 patients with NERD using a latent class analysis including clinical data from questionnaires, spirometry, atopy traits, blood eosinophilia, and urinary LTE4 concentrations as observable variables and found 4 classes [51]: class 1 patients showed moderate asthma course; class 2 showed mild asthma course; and class 3 and 4 patients showed severe asthma course. Blood eosinophilia and high urinary LTE4 were shown to be biomarkers that helped in class differentiation, especially for class 1 . We performed a two-step cluster analysis using 3 clinical criteria: atopy, CRS, and urticaria to identify phenotypic clusters. We found 4 subtypes: subtype 1 (NERD with CRS/atopy and no urticaria), subtype 2 (NERD with CRS and no urticaria/atopy), subtype 3 (NERD without CRS/urticaria), and subtype 4 (NERD with urticaria). Subtypes 1 and 2 showed more severe clinical courses with higher blood/sputum eosinophilia and frequent asthma exacerbation requiring systemic steroid burst [83]. Higher levels of urinary LTE4 were observed in subtypes 1 and 3. These findings suggested that the level of LTE4 was not only a strong biomarker of NERD; it could also be applied to specific subtypes and endotypes of NERD. Classifying NERD into subtypes using biomarkers such as urinary LTE4 will help in better management of NERD.

\section{Conclusion}

The most useful biomarker of NERD is urinary LTE4. Urinary LTE4 level can be used for distinguishing the phenotype (including subtypes) and for predicting the response to desensitization and prognosis. Sputum/blood eosinophil counts are also biomarkers that can be used to identify the endotype of NERD and to monitor the course of treatment. Serum periostin levels and HLA-DPB1 ( ${ }^{*} 0301$ and genetic polymorphisms) are suggested as useful biomarkers for predicting NERD phenotypes.

\section{Conflicts of Interest}

The authors have no competing interests.

\section{Acknowledgments}

This research was supported by a grant of the Korea Health Technology R\&D Project through the Korea Health Industry Development Institute (KHIDI) and funded by the Ministry of Health \& Welfare, Republic of Korea (Grant no. HI16C0992).

\section{References}

[1] M. Samter and R. F. Beers, "Intolerance to aspirin: clinical studies and consideration of its pathogenesis," Annals of Internal Medicine, vol. 68, no. 5, pp. 975-983, 1968.

[2] J. P. Rajan, N. E. Wineinger, D. D. Stevenson, and A. A. White, "Prevalence of aspirin-exacerbated respiratory disease among asthmatic patients: a meta-analysis of the literature," Journal of Allergy and Clinical Immunology, vol. 135, no. 3, pp. 676.e1-681.e1, 2015.

[3] J. H. Lee, T. Haselkorn, L. Borish, L. Rasouliyan, B. E. Chipps, and S. E. Wenzel, "Risk factors associated with persistent airflow limitation in severe or difficult-to-treat asthma: insights from the TENOR study," Chest Journal, vol. 132, no. 6, pp. 1882-1889, 2007.

[4] E. S. Group, "The ENFUMOSA cross-sectional European multicentre study of the clinical phenotype of chronic severe asthma," European Respiratory Journal, vol. 22, no. 3, pp. 470-477, 2003.

[5] D. C. Lin, R. K. Chandra, B. K. Tan et al., "Association between severity of asthma and degree of chronic rhinosinusitis," American Journal of Rhinology \& Allergy, vol. 25, no. 4, p. 205, 2011.

[6] K. Mascia, T. Haselkorn, Y. M. Deniz et al., "Aspirin sensitivity and severity of asthma: evidence for irreversible airway obstruction in patients with severe or difficult-to-treat asthma," Journal of Allergy and Clinical Immunology, vol. 116, no. 5, pp. 970-975, 2005.

[7] W. W. Stevens and R. P. Schleimer, "Aspirin-exacerbated respiratory disease as an endotype of chronic rhinosinusitis," Immunology and Allergy Clinics of North America, vol. 36, no. 4, pp. 669-680, 2016.

[8] S. E. Wenzel, "Asthma phenotypes: the evolution from clinical to molecular approaches," Nature Medicine, vol. 18, no. 5, pp. 716-725, 2012.

[9] J. Lötvall, C. A. Akdis, L. B. Bacharier et al., "Asthma endotypes: a new approach to classification of disease entities within the asthma syndrome," Journal of Allergy and Clinical Immunology, vol. 127, no. 2, pp. 355-360, 2011.

[10] J.-H. Kim, G.-S. Choi, J.-E. Kim et al., "Clinical course of patients with aspirin-exacerbated respiratory disease: can we predict the prognosis?," Pharmacogenomics, vol. 15, no. 4, pp. 449-457, 2014.

[11] D. L. Pham, J.-H. Lee, and H.-S. Park, "Aspirin-exacerbated respiratory disease: an update," Current Opinion in Pulmonary Medicine, vol. 23, no. 1, pp. 89-96, 2017.

[12] I. Agache, C. Akdis, M. Jutel, and J. Virchow, "Untangling asthma phenotypes and endotypes," Allergy, vol. 67, no. 7, pp. 835-846, 2012.

[13] G. P. Anderson, "Endotyping asthma: new insights into key pathogenic mechanisms in a complex, heterogeneous disease," The Lancet, vol. 372, no. 9643, pp. 1107-1119, 2008. 
[14] A. Szczeklik, E. Niżankowska, M. Duplaga, O. B. Of, and A. Investigators, "Natural history of aspirin-induced asthma," European Respiratory Journal, vol. 16, no. 3, pp. 432-436, 2000.

[15] D. K. Ledford and R. F. Lockey, "Aspirin or nonsteroidal antiinflammatory drug-exacerbated chronic rhinosinusitis," The Journal of Allergy and Clinical Immunology: In Practice, vol. 4, no. 4, pp. 590-598, 2016.

[16] N. Higashi, M. Taniguchi, H. Mita, H. Yamaguchi, E. Ono, and K. Akiyama, "Aspirin-intolerant asthma (AIA) assessment using the urinary biomarkers, leukotriene $\mathrm{E}_{4}\left(\mathrm{LTE}_{4}\right)$ and prostaglandin $\mathrm{D}_{2}\left(\mathrm{PGD}_{2}\right)$ metabolites," Allergology International, vol. 61, no. 3, pp. 393-403, 2012.

[17] A. R. Parker, A. G. Ayars, M. C. Altman, and W. R. Henderson, "Lipid mediators in aspirin-exacerbated respiratory disease," Immunology and Allergy Clinics of North America, vol. 36, no. 4, pp. 749-763, 2016.

[18] K. M. Buchheit and T. M. Laidlaw, "Update on the management of aspirin-exacerbated respiratory disease," Allergy, Asthma \& Immunology Research, vol. 8, no. 4, pp. 298-304, 2016.

[19] T. Yamashita, H. Tsuji, N. Maeda, K. Tomoda, and T. Kumazawa, "Etiology of nasal polyps associated with aspirin-sensitive asthma," Rhinology Supplement, vol. 8, pp. 15-24, 1988.

[20] C. A. Pérez-Novo, J. B. Watelet, C. Claeys, P. V. Cauwenberge, and C. Bachert, "Prostaglandin, leukotriene, and lipoxin balance in chronic rhinosinusitis with and without nasal polyposis," Journal of Allergy and Clinical Immunology, vol. 115, no. 6, pp. 1189-1196, 2005.

[21] H.-S. Park, D.-H. Nahm, K. Park, K.-S. Suh, and H. Yim, "Immunohistochemical characterization of cellular infiltrate in nasal polyp from aspirin-sensitive asthmatic patients," Annals of Allergy, Asthma \& Immunology, vol. 81, no. 3, pp. 219-224, 1998.

[22] R. Pods, D. Ross, S. Hülst, C. Rudack, and S. Maune, "RANTES, eotaxin and eotaxin-2 expression and production in patients with aspirin triad," Allergy, vol. 58, no. 11, pp. 1165-1170, 2003.

[23] E. D. Schryver, L. Devuyst, L. Derycke et al., "Local immunoglobulin E in the nasal mucosa: clinical implications," Allergy, Asthma \& Immunology Research, vol. 7, no. 4, pp. 321-331, 2015.

[24] M. Sanak, "Eicosanoid mediators in the airway inflammation of asthmatic patients: what is new?," Allergy, Asthma \& Immunology Research, vol. 8, no. 6, pp. 481-490, 2016.

[25] F. Gaber, K. Daham, A. Higashi et al., "Increased levels of cysteinyl-leukotrienes in saliva, induced sputum, urine and blood from patients with aspirin-intolerant asthma," Thorax, vol. 63, no. 12, pp. 1076-1082, 2008.

[26] L. Mastalerz, N. Celejewska-Wójcik, K. Wójcik et al., "Induced sputum eicosanoids during aspirin bronchial challenge of asthmatic patients with aspirin hypersensitivity," Allergy, vol. 69, no. 11, pp. 1550-1559, 2014.

[27] A. R. Fischer, M. A. Rosenberg, C. M. Lilly et al., "Direct evidence for a role of the mast cell in the nasal response to aspirin in aspirin-sensitive asthma," Journal of Allergy and Clinical Immunology, vol. 94, no. 6, pp. 1046-1056, 1994.

[28] P. E. Christie, P. Tagari, A. W. Ford-Hutchinson et al., "Urinary leukotriene $\mathrm{E}_{4}$ concentrations increase after aspirin challenge in aspirin-sensitive asthmatic subjects," The
American Review of Respiratory Disease, vol. 143, no. 5, Part 1, pp. 1025-1029, 1991.

[29] R. Oosaki, Y. Mizushima, H. Mita, T. Shida, K. Akiyama, and M. Kobayashi, "Urinary leukotriene $\mathrm{E}_{4}$ and 11dehydrothromboxane $B_{2}$ in patients with aspirin-sensitive asthma," Allergy, vol. 52, no. 4, pp. 470-473, 1997.

[30] M. Kumlin, B. Dahlén, T. Björck, O. Zetterström, E. Granström, and S. E. Dahlén, "Urinary excretion of leukotriene $\mathrm{E}_{4}$ and 11dehydro-thromboxane $\mathrm{B}_{2}$ in response to bronchial provocations with allergen, aspirin, leukotriene $\mathrm{D}_{4}$, and histamine in asthmatics," American Review of Respiratory Disease, vol. 146, no. 1, pp. 96-103, 1992.

[31] H. Mita, S. Endoh, M. Kudoh et al., "Possible involvement of mast-cell activation in aspirin provocation of aspirin-induced asthma," Allergy, vol. 56, no. 11, pp. 1061-1067, 2001.

[32] N. Higashi, M. Taniguchi, H. Mita, M. Osame, and K. Akiyama, "A comparative study of eicosanoid concentrations in sputum and urine in patients with aspirin-intolerant asthma," Clinical \& Experimental Allergy, vol. 32, no. 10, pp. 1484-1490, 2002.

[33] N. Higashi, H. Mita, E. Ono et al., "Profile of eicosanoid generation in aspirin-intolerant asthma and anaphylaxis assessed by new biomarkers," Journal of Allergy and Clinical Immunology, vol. 125, no. 5, pp. 1084.e6-1091.e6, 2010.

[34] L. Mastalerz, M. Sanak, A. Gawlewicz-Mroczka, A. Gielicz, A. Ćmiel, and A. Szczeklik, "Prostaglandin $\mathrm{E}_{2}$ systemic production in patients with asthma with and without aspirin hypersensitivity," Thorax, vol. 63, no. 1, pp. 2734, 2008.

[35] R. Divekar, J. Hagan, M. Rank et al., "Diagnostic utility of urinary LTE4 in asthma, allergic rhinitis, chronic rhinosinusitis, nasal polyps, and aspirin sensitivity," The Journal of Allergy and Clinical Immunology: In Practice, vol. 4, no. 4, pp. 665670, 2016.

[36] K. N. Cahill, J. C. Bensko, J. A. Boyce, and T. M. Laidlaw, "Prostaglandin $\mathrm{D}_{2}$ : a dominant mediator of aspirinexacerbated respiratory disease," Journal of Allergy and Clinical Immunology, vol. 135, no. 1, pp. 245-252, 2015.

[37] G. Y. Ban, K. Cho, S. H. Kim et al., "Metabolomic analysis identifies potential diagnostic biomarkers for aspirinexacerbated respiratory disease," Clinical \& Experimental Allergy, vol. 47, no. 1, pp. 37-47, 2017.

[38] P. J. Daffern, D. Muilenburg, T. E. Hugli, and D. D. Stevenson, "Association of urinary leukotriene $\mathrm{E}_{4}$ excretion during aspirin challenges with severity of respiratory responses," Journal of Allergy and Clinical Immunology, vol. 104, no. 3, pp. 559564, 1999.

[39] T. M. Laidlaw and J. A. Boyce, "Aspirin-exacerbated respiratory disease-new prime suspects," New England Journal of Medicine, vol. 374, no. 5, pp. 484-488, 2016.

[40] G. Bochenek, K. Nagraba, E. Niżankowska, and A. Szczeklik, "A controlled study of $9 \alpha, 11 \beta-\mathrm{PGF}_{2}$ (a prostaglandin $\mathrm{D}_{2}$ metabolite) in plasma and urine of patients with bronchial asthma and healthy controls after aspirin challenge," Journal of Allergy and Clinical Immunology, vol. 111, no. 4, pp. 743749, 2003.

[41] K. M. Buchheit, K. N. Cahill, H. R. Katz et al., "Thymic stromal lymphopoietin controls prostaglandin $\mathrm{D}_{2}$ generation in patients with aspirin-exacerbated respiratory disease," Journal of Allergy and Clinical Immunology, vol. 137, no. 5, pp. 1566.e5-1576.e5, 2016. 
[42] G. Bochenek, E. Niżankowska, A. Gielicz, M. Świerczyńska, and A. Szczeklik, "Plasma $9 \alpha, 11 \beta-\mathrm{PGF}_{2}$, a $\mathrm{PGD}_{2}$ metabolite, as a sensitive marker of mast cell activation by allergen in bronchial asthma," Thorax, vol. 59, no. 6, pp. 459-464, 2004.

[43] P. Sestini, L. Armetti, G. Gambaro et al., "Inhaled PGE2 prevents aspirin-induced bronchoconstriction and urinary LTE4 excretion in aspirin-sensitive asthma," American Journal of Respiratory and Critical Care Medicine, vol. 153, no. 2, pp. 572-575, 1996.

[44] C. Picado, J. C. Fernandez-Morata, M. Juan et al., "Cyclooxygenase-2 mRNA is downexpressed in nasal polyps from aspirin-sensitive asthmatics," American Journal of Respiratory and Critical Care Medicine, vol. 160, no. 1, pp. 291296, 1999.

[45] J. Roca-Ferrer, F. J. Garcia-Garcia, J. Pereda et al., "Reduced expression of COXs and production of prostaglandin $\mathrm{E}_{2}$ in patients with nasal polyps with or without aspirin-intolerant asthma," Journal of Allergy and Clinical Immunology, vol. 128, no. 1, pp. 66.e1-72.e1, 2011.

[46] F. Roviezzo, B. D'agostino, V. Brancaleone et al., "Systemic administration of sphingosine-1-phosphate increases bronchial hyperresponsiveness in the mouse," American Journal of Respiratory Cell and Molecular Biology, vol. 42, no. 5, pp. 572-577, 2010.

[47] T. S. Worgall, A. Veerappan, B. Sung et al., "Impaired sphingolipid synthesis in the respiratory tract induces airway hyperreactivity," Science Translational Medicine, vol. 5, no. 186, pp. 186ra67-186ra67, 2013.

[48] H. K. T. Trinh, S.-C. Kim, K. Cho et al., "Exploration of the sphingolipid metabolite, sphingosine-1-phosphate and sphingosine, as novel biomarkers for aspirin-exacerbated respiratory disease," Scientific Reports, vol. 6, 2016.

[49] S. J. Szefler, S. Wenzel, R. Brown et al., "Asthma outcomes: biomarkers," Journal of Allergy and Clinical Immunology, vol. 129, no. 3, pp. S9-S23, 2012.

[50] A. S. Cowburn, K. Sladek, J. Soja et al., "Overexpression of leukotriene C4 synthase in bronchial biopsies from patients with aspirin-intolerant asthma," Journal of Clinical Investigation, vol. 101, no. 4, p. 834, 1998.

[51] G. Bochenek, J. Kuschill-Dziurda, K. Szafraniec, H. Plutecka, A. Szczeklik, and E. Nizankowska-Mogilnicka, "Certain subphenotypes of aspirin-exacerbated respiratory disease distinguished by latent class analysis," Journal of Allergy and Clinical Immunology, vol. 133, no. 1, pp. 98.e6-103.e6, 2014.

[52] M. Kupczyk, Z. Kurmanowska, I. Kupryś-Lipińska, M. Bocheńska-Marciniak, and P. Kuna, "Mediators of inflammation in nasal lavage from aspirin intolerant patients after aspirin challenge," Respiratory Medicine, vol. 104, no. 10, pp. 1404-1409, 2010.

[53] R. H. Green, C. E. Brightling, S. McKenna et al., "Asthma exacerbations and sputum eosinophil counts: a randomised controlled trial," The Lancet, vol. 360, no. 9347, pp. 17151721, 2002.

[54] R. Louis, L. C. Lau, A. O. Bron, A. C. Roldaan, M. Radermecker, and R. Djukanovic, "The relationship between airways inflammation and asthma severity," American Journal of Respiratory and Critical Care Medicine, vol. 161, no. 1, pp. 9-16, 2000.

[55] S. J. Conway, K. Izuhara, Y. Kudo et al., "The role of periostin in tissue remodeling across health and disease," Cellular and Molecular Life Sciences, vol. 71, no. 7, pp. 1279-1288, 2014.
[56] K. Izuhara, S. Ohta, and J. Ono, "Using periostin as a biomarker in the treatment of asthma," Allergy, Asthma \& Immunology Research, vol. 8, no. 6, pp. 491-498, 2016.

[57] M.-A. Kim, K. Izuhara, S. Ohta et al., "Association of serum periostin with aspirin-exacerbated respiratory disease," Annals of Allergy, Asthma \& Immunology, vol. 113, no. 3, pp. 314-320, 2014.

[58] D. Hamilos, D. Leung, D. Huston, A. Kamil, R. Wood, and Q. Hamid, "GM-CSF, IL-5 and RANTES immunoreactivity and mRNA expression in chronic hyperplastic sinusitis with nasal polyposis (NP)," Clinical and Experimental Allergy, vol. 28, no. 9, pp. 1145-1152, 1998.

[59] T. Liu, Y. Kanaoka, N. A. Barrett et al., "Aspirin-exacerbated respiratory disease involves a cysteinyl leukotriene-driven IL-33-mediated mast cell activation pathway," The Journal of Immunology, vol. 195, no. 8, pp. 3537-3545, 2015.

[60] R. Pezato, M. Świerczyńska-Krępa, E. NiżankowskaMogilnicka et al., "Systemic expression of inflammatory mediators in patients with chronic rhinosinusitis and nasal polyps with and without aspirin exacerbated respiratory disease," Cytokine, vol. 77, pp. 157-167, 2016.

[61] J. W. Steinke, L. Liu, P. Huyett, J. Negri, S. C. Payne, and L. Borish, "Prominent role of IFN- $\gamma$ in patients with aspirinexacerbated respiratory disease," Journal of Allergy and Clinical Immunology, vol. 132, no. 4, pp. 856.e3-865.e3, 2013.

[62] N. Li, "Platelet-lymphocyte cross-talk," Journal of Leukocyte Biology, vol. 83, no. 5, pp. 1069-1078, 2008.

[63] J. Jawień, M. Łomnicka, R. Korbut, and S. Chłopicki, "The involvement of adhesion molecules and lipid," Journal of Physiology and Pharmacology, vol. 56, no. 4, pp. 637-648, 2005.

[64] C. Mitsui, K. Kajiwara, H. Hayashi et al., "Platelet activation markers overexpressed specifically in patients with aspirinexacerbated respiratory disease," Journal of Allergy and Clinical Immunology, vol. 137, no. 2, pp. 400-411, 2016.

[65] T. M. Laidlaw, M. S. Kidder, N. Bhattacharyya et al., "Cysteinyl leukotriene overproduction in aspirin-exacerbated respiratory disease is driven by platelet-adherent leukocytes," Blood, vol. 119, no. 16, pp. 3790-3798, 2012.

[66] J. Dekker, E. Nizankowska, M. Schmitz-Schumann et al., "Aspirin-induced asthma and HLA-DRB1 and HLA-DPB1 genotypes," Clinical \& Experimental Allergy, vol. 27, no. 5, pp. 574-577, 1997.

[67] H.-S. Park, S.-H. Kim, A. P. Sampson, K.-W. Lee, and C.-S. Park, "The HLA-DPB1* 0301 marker might predict the requirement for leukotriene receptor antagonist in patients with aspirin-intolerant asthma," Journal of Allergy and Clinical Immunology, vol. 114, no. 3, pp. 688-689, 2004.

[68] J. H. Choi, K. W. Lee, H. B. Oh et al., "HLa association in aspirin-intolerant asthma: DPB $1 * 0301$ as a strong marker in a Korean population," Journal of Allergy and Clinical Immunology, vol. 113, no. 3, pp. 562-564, 2004.

[69] B. L. Park, T.-H. Kim, J.-H. Kim et al., "Genome-wide association study of aspirin-exacerbated respiratory disease in a Korean population," Human Genetics, vol. 132, no. 3, pp. 313-321, 2013.

[70] S.-H. Kim, B.-Y. Cho, H. Choi et al., "The SNP rs3128965 of HLA-DPB1 as a genetic marker of the AERD phenotype," PLoS One, vol. 9, no. 12, article e111220, 2014.

[71] M. Sanak, M. Pierzchalska, S. Bazan-Socha, and A. Szczeklik, "Enhanced expression of the leukotriene C4 synthase due to overactive transcription of an allelic variant associated with 
aspirin-intolerant asthma," American Journal of Respiratory Cell and Molecular Biology, vol. 23, no. 3, pp. 290-296, 2000.

[72] Y. Zhang, H. Huang, J. Huang et al., "The $-444 \mathrm{~A} / \mathrm{C}$ polymorphism in the LTC4S gene and the risk of asthma: a meta-analysis," Archives of Medical Research, vol. 43, no. 6, pp. 444-450, 2012.

[73] J.-H. Choi, H.-S. Park, H.-B. Oh et al., "Leukotriene-related gene polymorphisms in ASA-intolerant asthma: an association with a haplotype of 5-lipoxygenase," Human Genetics, vol. 114, no. 4, pp. 337-344, 2004.

[74] S. H. Kim, J. M. Oh, Y. S. Kim et al., "Cysteinyl leukotriene receptor 1 promoter polymorphism is associated with aspirin-intolerant asthma in males," Clinical \& Experimental Allergy, vol. 36, no. 4, pp. 433-439, 2006.

[75] J. S. Park, H. S. Chang, C.-S. Park et al., “Association analysis of cysteinyl-leukotriene receptor 2 (CYSLTR2) polymorphisms with aspirin intolerance in asthmatics," Pharmacogenetics and Genomics, vol. 15, no. 7, pp. 483-492, 2005.

[76] N. Jinnai, T. Sakagami, T. Sekigawa et al., "Polymorphisms in the prostaglandin E2 receptor subtype 2 gene confer susceptibility to aspirin-intolerant asthma: a candidate gene approach," Human Molecular Genetics, vol. 13, no. 24, pp. 3203-3217, 2004.

[77] S.-H. Kim, Y.-K. Kim, H.-W. Park et al., "Association between polymorphisms in prostanoid receptor genes and aspirinintolerant asthma," Pharmacogenetics and Genomics, vol. 17, no. 4, pp. 295-304, 2007.

[78] B.-L. Park, S.-M. Park, J.-S. Park et al., “Association of PTGER gene family polymorphisms with aspirin intolerant asthma in Korean asthmatics," BMB Reports, vol. 43, no. 6, pp. 445449, 2010.

[79] N. Palikhe, S. H. Kim, B. Y. Cho, Y. M. Ye, G. S. Choi, and H. S. Park, "Genetic variability in CRTH2 polymorphism increases eotaxin-2 levels in patients with aspirin exacerbated respiratory disease," Allergy, vol. 65, no. 3, pp. 338-346, 2010.

[80] S.-H. Kim, H.-H. Jeong, B.-Y. Cho et al., "Association of fourlocus gene interaction with aspirin-intolerant asthma in Korean asthmatics," Journal of Clinical Immunology, vol. 28, no. 4, pp. 336-342, 2008.

[81] N. S. Palikhe, S.-H. Kim, B.-Y. Cho, Y. M. Ye, G. Y. Hur, and H. S. Park, "Association of three sets of high-affinity IgE receptor (FcepsilonR1) polymorphisms with aspirin-intolerant asthma," Respiratory Medicine, vol. 102, no. 8, pp. 11321139, 2008.

[82] S. H. Kim, J. S. Bae, J. W. Holloway et al., "A polymorphism of MS4A2 $(-109 \mathrm{~T}>\mathrm{C})$ encoding the $\beta$-chain of the high-affinity immunoglobulin $\mathrm{E}$ receptor $(\mathrm{FccR} 1 \beta)$ is associated with a susceptibility to aspirin-intolerant asthma," Clinical \& Experimental Allergy, vol. 36, no. 7, pp. 877-883, 2006.

[83] H. Y. Lee, Y. M. Ye, S. H. Kim et al., "Identification of phenotypic clusters of non-steroidal anti-inflammatory drugs exacerbated respiratory disease," Allergy, vol. 72, no. 4, pp. 616-626, 2017. 


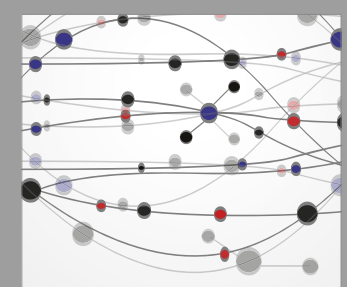

The Scientific World Journal
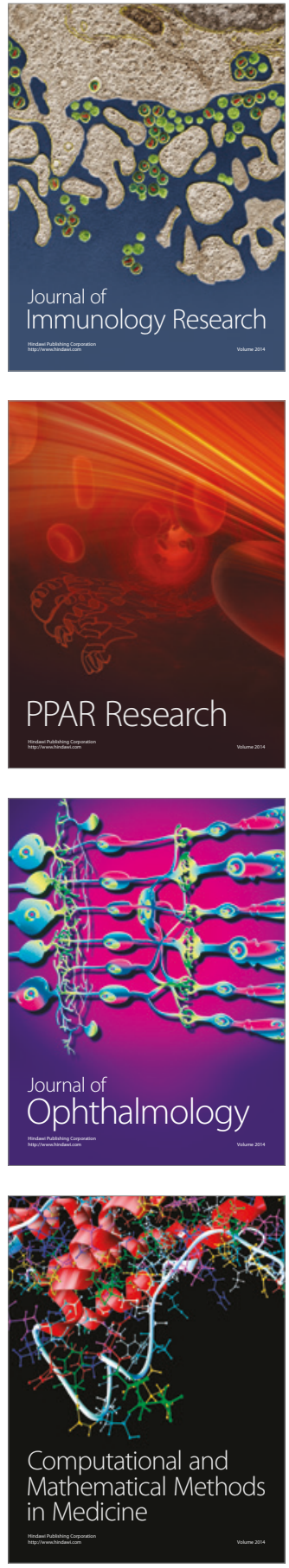

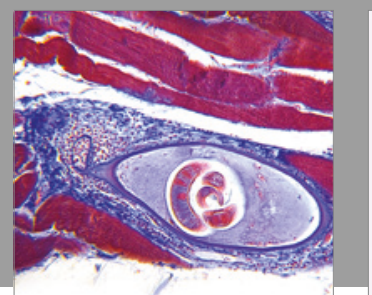

Gastroenterology Research and Practice
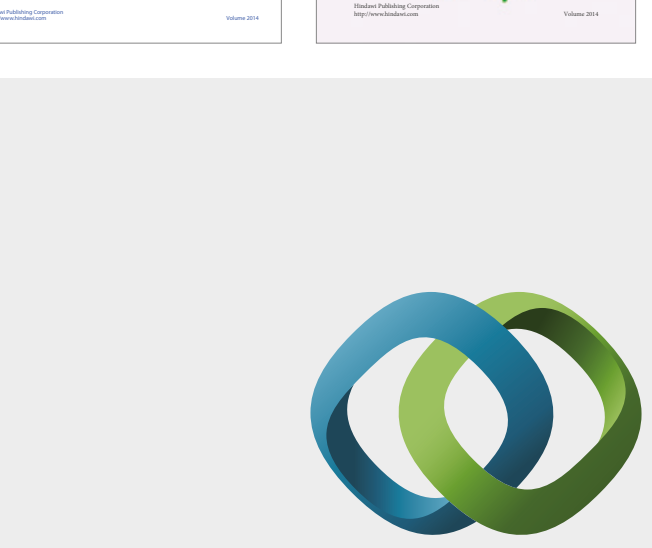

\section{Hindawi}

Submit your manuscripts at

https://www.hindawi.com
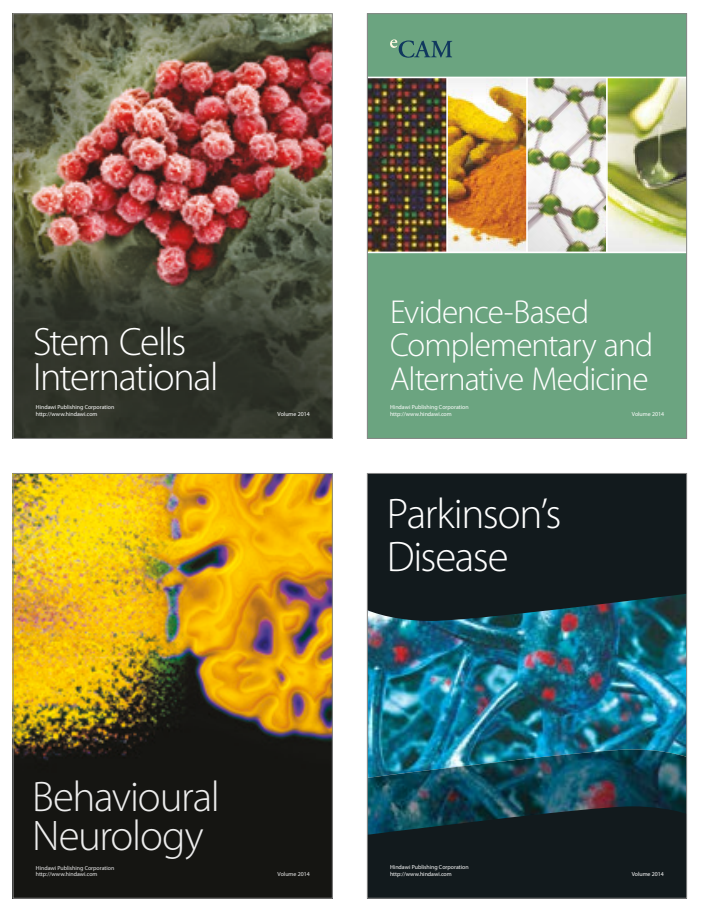
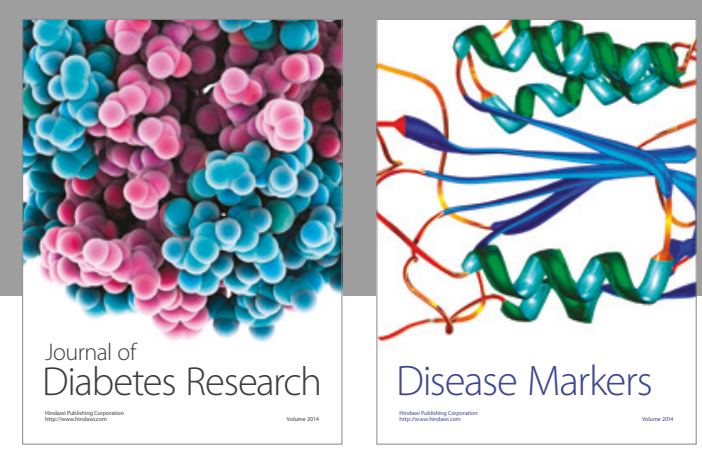

Disease Markers
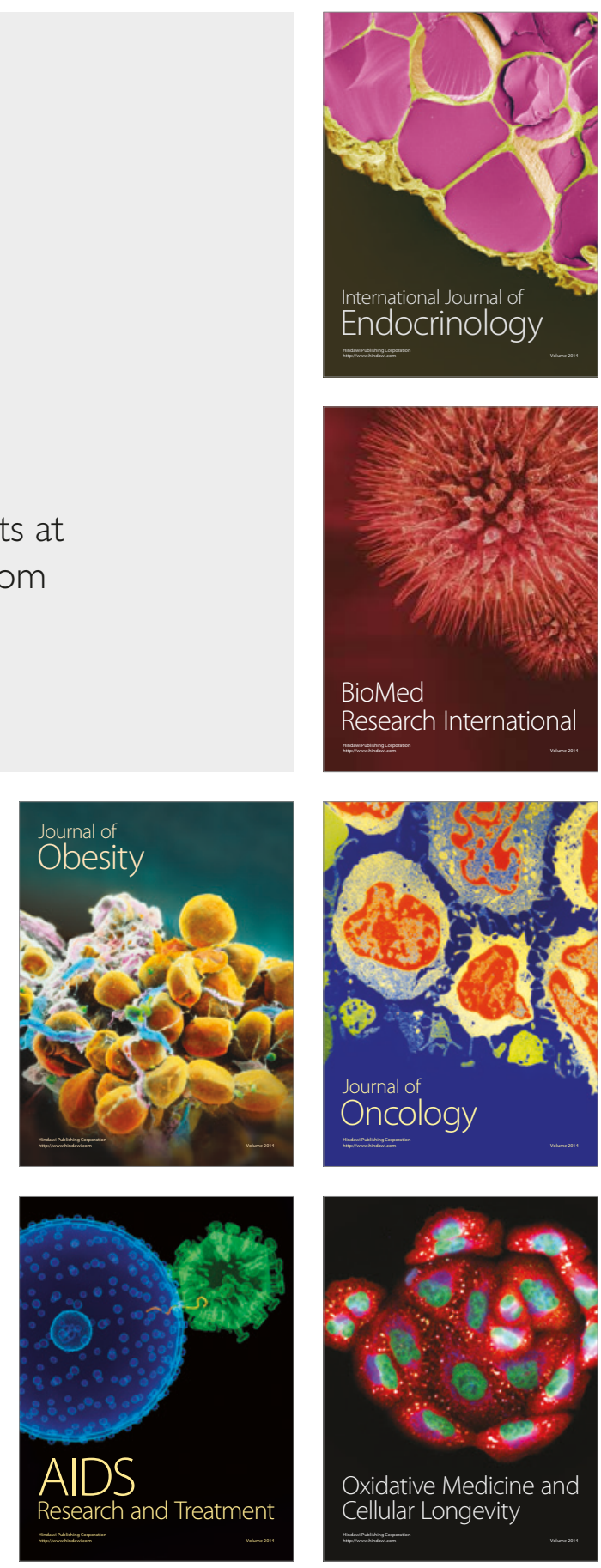